\title{
Classification of odontogenic Cysts: A Review.
}

\author{
Dr. Bharat Sumbh ${ }^{1}$, Dr. Shweta Gangotri Sumbh ${ }^{2}$, Dr. Pooja Jain ${ }^{3}$, \\ Dr. Jaishree Pagare ${ }^{4}$ \\ ${ }^{I}$ MDS-Oral \& Maxillofacial Surgery, Associate Professor \&HOD (Dept. Dentistry, GMC, Raigarh, \\ Chattisgarh \\ India.) \\ ${ }^{2}$ MDS - Oral Medicine \& Radiology, Assistant Professor (Dept. Oral Medicine \& Radiology, Government \\ Dental College , Aurangabad, Maharashtra, India.) \\ ${ }^{3}$ MDS - Oral Medicine \& Radiology, Assistant Professor (Dept. Oral Medicine \& Radiology, Government \\ Dental College , Aurangabad, Maharashtra, India.) \\ ${ }^{4}$ MDS - Oral Medicine \& Radiology, Associate Professor \& HOD (Dept. Oral Medicine \& Radiology, \\ Government Dental College , Aurangabad, Maharashtra, India.)
}

\begin{abstract}
Classification of Odontogenic cyst is very important for diagnosis and proper management of the patient. Various tumors mimic the clinical features of cysts and thus can be confused with the same. Cysts that arise from tissue(s) that would normally develop into teeth are referred to as odontogenic cysts. Other cysts of the jaws are termed non-odontogenic cysts. Non-odontogenic cysts arise from tissues other than those involved in tooth development may contain structures such as epithelium from the nose, maxillary sinus etcAn attempt has been made in this article to provide and update the knowledge of classification system so as to assess the clinician, researchers and academicians in the categorization of different varieties of cyst and their subsequent management.
\end{abstract}

Keywords: Odontogenic, cyst, non - odontogenic.

\section{Introduction}

Classification of Odontogenic cysts is very important for diagnosis and proper management of the patient. Various tumors mimic the clinical features of cysts and thus can be confused with the same.A cyst is a pathological epithelial lined cavity that is filled with fluid or semifluid material and usually grows from internal pressure generated by fluid being drawn into the cavity from osmosis (hydrostatic pressure).A cyst is defined as "a pathological cavity having fluid, semi-fluid, or gaseous contents and which is not created by accumulation of pus"- Kramer 1974. ${ }^{1}$ The bones of jaws , the mandible and maxilla, are the bones with the highest prevalence of cysts in the human body due to the abundant amount of epithelial remnants in the jaws.Cysts that arise from tissue(s) that would normally develop into teeth are referred to as odontogenic cysts. Other cysts of the jaws are termed as non-odontogenic cysts. Non-odontogenic cysts arise from tissues other than those involved in tooth development may contain structures such as epithelium from the nose, maxillary sinus etc. ${ }^{1}$ The different classifications of cysts are as follows:

$>$ Classification of cysts given by WHO 1992 \& 2005:

\begin{tabular}{|l|lr|lr|}
\hline Classification of epithelial jaw cysts & Inflammatory cysts \\
\hline & Developmental cysts & cyst & Radicular & cyst: \\
Odontogenic cysts & Follicular & cyst & residual \\
& Eruption & cyst lateral, & Periodontal cyst & \\
& Gingival periodontal & & \\
& Lateral & & \\
& Glandular odontogenic cyst & & \\
\hline $\begin{array}{l}\text { Non-odontogenic } \\
\text { cysts }\end{array}$ & $\begin{array}{l}\text { Cyst of the nasopalatine duct } \\
\text { Nasolabial cyst }\end{array}$ & & \\
\hline
\end{tabular}

The above classification is based on clinical, radiolographic and histopathological examinations according to the World Health Organisation classification of 1992 (Kramer and Pindborg 1992).

\begin{tabular}{|l|l|l|}
\hline Epithelial & Non odontogenic & \multirow{2}{*}{ Non epithelial } \\
\cline { 1 - 2 } Odontogenic & \multirow{2}{*}{ Naumatic cyst } \\
\cline { 1 - 2 } Developmental & Inflammatory & \\
\hline Gingival cyst of newborn & Radicular & \\
\hline Primordial cyst & & \\
\hline
\end{tabular}




\begin{tabular}{|l|l|l|l|}
\hline $\begin{array}{l}\text { Follicular cyst } \\
\text { Eruption cyst } \\
\text { Lateral periodontal cyst }\end{array}$ & Residual & & $\begin{array}{l}\text { Aneurysmal bone } \\
\text { cyst }\end{array}$ \\
\hline Adult gingival cyst & Paradental & Nasopalatine cyst & Stafne's bone cyst \\
\hline $\begin{array}{l}\text { Odontogenic-glandular } \\
\text { cyst }\end{array}$ & & & \\
\hline
\end{tabular}

The above classification is given by WHO 2005. ${ }^{4,5}$

$>$ According to Shear cysts are classified under three main headings: ${ }^{1}$

I Cysts of the jaws

II Cysts associated with the maxillary antrum

III Cysts of the soft tissues of the mouth, face, neck and salivary glands.

The cysts of the jaws are divided into those that are:

\section{Cysts of the jaws}

A Epithelial-lined cysts

1. Developmental origin

(a) Odontogenic

i Gingival cyst of infants

ii Odontogenic keratocyst

iii Dentigerous cyst

iv Eruption cyst

$\mathbf{v}$ Gingival cyst of adults

vi Developmental lateral periodontal cyst

vii Botryoid odontogenic cyst

viii Glandular odontogenic cyst

ix Calcifying odontogenic cyst

\section{(b) Non-odontogenic}

i Midpalatal raphé cyst of infants

ii Nasopalatine duct cyst

iii Nasolabial cyst

\section{Inflammatory origin}

i Radicular cyst, apical and lateral

ii Residual cyst

iii Paradental cyst and juvenile paradental cyst

iv Inflammatory collateral cyst

B Non-epithelial-lined cysts

1. Solitary bone cyst

2 .Aneurysmal bone cyst

II Cysts associated with the maxillary antrum

1. Mucocele

2 . Retention cyst

3. Pseudocyst

4. Postoperative maxillary cyst

III Cysts of the soft tissues of the mouth, face and neck

1. Dermoid and epidermoid cysts

2. Lymphoepithelial (branchial) cyst

3. Thyroglossal duct cyst

4. Anterior median lingual cyst (intralingual cyst of foregut origin)

5. Oral cysts with gastric or intestinal epithelium (oral alimentary tract cyst)

6. Cystic hygroma

7. Nasopharyngeal cyst

8. Thymic cyst

9. Cysts of the salivary glands: mucous extravasation cyst; mucous retention cyst; ranula; polycystic (dysgenetic) disease of the parotid 
10. Parasitic cysts: hydatid cyst; Cysticercus cellulosae; trichinosis

\section{$>$ Neville classified odontogenic cysts as follows: ${ }^{6}$}

\section{Developmental}

1. Dentigerous cyst

2. Eruption cyst

3. Odontogenic keratocyst

4. Orthokeratinized odontogenic cyst

5. Gingival (alveolar) cyst of newborn

6. Gingival cyst of adult

7. Lateral Periodontal cyst

8. Calcifing odontogenic cyst

9. Glandular odontogenic cyst.

\section{Inflammatory}

1. Periapical

2. Residual periapical (radicular) cyst

3. Buccal bifurcation cyst

\section{Classification given by Joseph Regezi : ${ }^{7}$}

\begin{tabular}{|l|l|l|l|}
\hline Type & source & Origin of rests & Cyst example \\
\hline Odontogenic rests & Rest of malassez & Epithelial root sheath & Peiapical (Radicular) cyst \\
\hline & $\begin{array}{l}\text { Reduced enamel } \\
\text { epithelium }\end{array}$ & Enamel organ & Dentigerous cyst \\
\hline & $\begin{array}{l}\text { Rests of dental lamina } \\
\text { (Rest of Serres) }\end{array}$ & $\begin{array}{l}\text { Epithelial connection between } \\
\text { mucosa and enamel organ }\end{array}$ & $\begin{array}{l}\text { Odontogenic kingival (alveolar) cyst of } \\
\text { newborn, Gingival cyst of } \\
\text { adult,Lateral Periodontal cyst, } \\
\text { Glandular odontogenic cyst. }\end{array}$ \\
\hline $\begin{array}{l}\text { Non odontogenic } \\
\text { rests }\end{array}$ & $\begin{array}{l}\text { Remnants } \\
\text { Nasopalatine duct }\end{array}$ & $\begin{array}{l}\text { Paired nasopalatine duct } \\
\text { (vestigial) }\end{array}$ & Nasopalatine canal cyst \\
\hline
\end{tabular}

\section{$>$ Shafer's Classification for odontogenic cyst: ${ }^{8}$}

\section{Classification based on etiology:}

Developmental: Unknown origin but are not the result of an inflammatory reaction

Dentigerous cyst

Eruption cyst

Odontogenic keratocyst

Gingival (alveolar) cyst of newborn

Gingival cyst of adult

Lateral Periodontal cyst

Calcifying odontogenic cyst

Glandular odontogenic cyst.

\section{Inflammatory}

Periapical

Residual periapical (radicular) cyst

Paradental cyst

\section{Classification by tissue of origin}

$>$ Derived from rests of Malassez

Periapical cyst

Residual cyst

Derived from reduced enamel epithelial

Dentigerous cyst

Eruption cyst

Derived from dental lamina( rest of Serres)

Odontogenic keratocyst

Gingival (alveolar) cyst of newborn

Gingival cyst of adult 
Lateral Periodontal cyst

Calcifying odontogenic cyst

Glandular odontogenic cyst.

\section{Unclassified}

Paradental cyst

\section{Calcifying odontogenic cyst}

The new classification of head and neck tumors was published by the World Health Organisation in July 2005 (Barnes et al. 2005). In this the odontogenic keratocysts are considered as benign tumours, meaning thatthey are now classified as odontogenic tumours. Odontogenic keratocyst is now defined as a benign tumour and classified as keratocystic odontogenic tumour.This change was based on the knowledge that odontogenic keratocysts more closely correspond to neoplastic lesions. Findings regarding genetic changes in Gorlin-Goltz syndrome (nevoid basal cell carcinoma syndrome) have led to reclassification of odontogenic keratocysts. Note: The reclassification and new molecular genetics findings do not have any clinical implications in terms of treatment planning (Reichart et al. 2006).

\section{Discussion}

Classification of cysts is an academic exercise that has developed over many years. Various researchers had put forth several classifications each with its salient features. This review lists the earliest and recently revised classifications. The purpose of the present article is to list the classification schemes proposed by various authors so as to facilitate the adoption of a uniform terminology and improve communication between clinicians, pathologists and surgeons.WHO in 1992 has classified cysts into two main categories and further divided it into developmental and inflammatory ${ }^{3}$. This is was a simple classification but does not include CEOC in odontogenic variety. Non odontogenic cysts like soft tissue cysts and cyst involving the maxillary antrum has not been included in this classification. WHO in 2005 reclassified the cysts broadly under epithelial and non epithelial categories which further included odontogenic and non odontogenic types.Shear has given a broader classification of cysts giving a better understanding of cystic lesions of head, neck and face thus assisting proper management. In this classification OKC is included in the odontogenic variety but according to WHO's new classification of benign tumors 2005 (Barnes et al. 2005) the odontogenic keratocyst is defined as benign keratocystic odontogenic tumor suggesting that $\mathrm{OKC}$ is now not being considered as a cystic entity.Neville has classified cysts into two categories viz. developmental and inflammatory depending on their pathogenesis. ${ }^{6}$ This scheme of classification does not distinguish odontogenic and the non odontogenic variety. OKC and OOKC have been included into the developmental variety but as discussed earlier OKC is now considered as a benign tumor.Regezi has classified cysts giving more importance to the origin, source of epithelium and the type of development (odontogenic and non odontogenic). ${ }^{7}$ Non odontogenic variety includes only nasopalatine duct cyst, rest of this variety are not considered. OKC is considered as odontogenic cyst and CEOC is not included in this classification.Shafer has classified cysts according to the etiological factors as developmental and inflammatory, tissue of origin and unclassified type. Again OKC is considered as cyst and not a tumor.Both Regezi's and Shafer's classification showed repetition of same cysts under different categories.Overall Shear classifies each and every cyst systematically helping in the diagnosis, communication and proper management of the cystic lesions. Shear's classification includes all the odontogenic and non odontogenic cysts of head, neck and face avoiding need for further reference.

\section{Conclusion}

An attempt has been made to provide and update the knowledge of classification system so as to assess the clinician, researchers and academicians in the categorization of different varieties of cysts and their subsequent management.

\section{References}

[1]. Shear M, Speight PM. Cysts of the oral and maxillofacial region.4th ed. Ch. 1. Oxford: Blackwell Munksgaard; 2007.

[2]. Boehme K, Morgenroth K . Retrospective histological classification of jaw cysts .DZZ 1993; $48: 177$.

[3]. Peter E. Larsen, Arden K. Hegtvedt . Odontogenesis and Odontogenic Cysts and Tumors. Chapter 78. e- book

[4]. Sergio Núñez-Urrutia , Rui Figueiredo . Retrospective clinicopathological study of 418 odontogenic cysts. Med Oral Patol Oral Cir Bucal. 2010; Sep 1;15 (5):e767-73.

[5]. Barnes L, Eveson JW, Reichart P, Sidransky D. World Health Organization, classification of tumors, pathology and genetics. Head and neck tumors, IARC Press, Lyon;2005.

[6]. Neville, Brad W.; Damm, Douglas D.; Allen, Carl M.; Bouquot, Jerry E. Oral \& Maxillofacial Pathology (2nd edition). Philadelphia, PA: W.B. Saunders Company. 2002 ; pp. 590-609.

[7]. Regezi, Joseph A., James J. Sciubba, and Richard CK Jordan. Oral pathology: clinical pathologic correlations. Elsevier Health Sciences, 2016; $4^{\text {th }}$ edition.

[8]. Rajendran, R. Shafer's textbook of oral pathology. Elsevier India, 2009. 7th edition; pg 260. 